\title{
Desafios do Fazer Docente nas Salas de Recursos Multifuncionais (SRM)
}

\author{
Séfora Lima de Figueiredo ${ }^{1}$ \\ ${ }^{1}$ Universidade Estadual da Paraíba, PB, Brasil.
}

\author{
Edil Ferreira da Silva ${ }^{1}$ \\ ${ }^{1}$ Universidade Estadual da Paraíba, PB, Brasil.
}

Resumo: Este artigo objetiva compreender a relação entre o prescrito na legislação brasileira para o desenvolvimento do trabalho nas salas de recursos multifuncionais (SRM) e a realidade do trabalho na rede municipal de ensino de uma cidade do Nordeste brasileiro, além de mostrar como se mobilizam subjetivamente as professoras desse local frente às condições e organização do trabalho que lhes são impostas. As SRM são espaços instituídos nas escolas públicas brasileiras para atender ao direito universal à educação aos que apresentam deficiências, transtornos globais do desenvolvimento, altas habilidades ou superdotação, por meio do Atendimento Educacional Especializado (AEE). É um serviço recente e pouco conhecido nacionalmente; por isso, é permeado de nuances e desafios que somente as docentes executantes conseguem externar. A pesquisa adotou a Psicodinâmica do Trabalho (PDT) como arcabouço teórico-metodológico e usou, como método de coleta de dados, visitas institucionais e encontros coletivos de discussão. Oito SRM foram visitadas na etapa da observação e 4 professoras participaram do grupo de discussão coletiva. Os resultados demonstraram que as docentes "se desdobram" para dar conta da defasagem entre o prescrito e a realidade do trabalho no AEE. Diante dos constrangimentos e da sobrecarga relacionados à organização do trabalho, vivenciam constantes sofrimentos patológicos e criativos, portanto, se mostraram ativas nas escolas. Há um adoecimento psíquico atrelado ao fazer dessas docentes, algumas das quais pediram para deixar o AEE.

Palavras-chave: Psicodinâmica do Trabalho, Saúde Mental e Trabalho, Educação Inclusiva, Atendimento Educacional Especializado, Atividade Docente.

\section{Challenges of Teaching in Multifunctional Resource Rooms (SRMs)}

\begin{abstract}
This article aims to understand the relationship between what is prescribed in Brazilian legislation for the development of work in the Multifunctional Resource Rooms (SRMs) and the real work of the municipal education network of a city in the northeast of Brazil, and show how these teachers subjectively mobilize in view of the conditions and organization of work imposed on them. The Multifunctional Resource Rooms (SRMs) are established spaces in Brazilian public schools to comply with the universal right to education to those with disabilities, global developmental disorders, high skills, or gifts by the Specialized Educational Assistance (SEA). It's a recent service and barely known nationally, and that is why it is permeated by nuances and challenges that only the acting teachers can externalize. The search adopted the Psychodynamics of Work as a theoretical-methodological framework and institutional visits and collective discussion meetings as method of data collection. We visited eight SRMs during the observational stage and four teachers participated in the collective discussion meetings. The results showed that the teachers make do to account for the gap between the prescribed and the actual work of SEA. They confront the embarrassment and the overload related to the work organization that keep them in constant pathological and creative suffering for them to show themselves as active in schools. The work of these teachers is tied to a worsening psychic condition leading some to request to leave the SEA.
\end{abstract}

Keywords: Psychodynamics of Work, Mental Health and Work, Inclusive Education, Specialized Educational Assistance, Teachers Work. 


\title{
Desafíos del Hacer Docente en las Salas de Recursos Multifuncionales (SRM)
}

\begin{abstract}
Resumen: Este artículo tiene como objetivo comprender la relación entre lo prescrito por la legislación brasileña en cuanto al desarrollo del trabajo en las Salas de Recursos Multifuncionales (SRM) y el trabajo real de la red de educación municipal de una ciudad del noreste de Brasil, así como mostrar cómo movilizar a los profesores de este lugar en vista de las condiciones y organización del trabajo que se les imponen. Las SRM son espacios instituidos en las escuelas públicas brasileñas para atender el derecho universal a la educación a quienes presentan discapacidades, trastornos globales del desarrollo, altas habilidades o superdotación, mediante la Atención Educativa Especializada (AEE). Este es un servicio reciente y poco conocido en el país; por eso es permeado de matices y desafíos que solamente las docentes ejecutantes consiguen externar. La investigación adoptó la Psicodinámica del Trabajo como base teóricometodológico y como método de recolección de datos las visitas institucionales y encuentros colectivos de discusión. Ocho SRM fueron visitadas en la etapa de observación y cuatro profesoras participaron en el grupo de discusión colectiva. Los resultados demostraron que las docentes trabajan mucho para dar cuenta del retraso entre lo prescrito y la realidad del trabajo en la AEE. Ante las restricciones y la sobrecarga laboral, vivencian sufrimientos patológicos y creativos, pero se mostraron activas en las escuelas. Hay una enfermedad psíquica sujeta al hacer de estas docentes, y algunas de ellas solicitaron salir de la AEE.
\end{abstract}

Palabras clave: Psicodinámica del Trabajo, Salud Mental y Trabajo, Educación Inclusiva, Atención Educativa Especializada, Actividad Docente.

\section{Introdução}

Nas últimas três décadas do século XX, o capitalismo foi alvo de transformações que marcaram de forma contundente o modo de organização do trabalho, as formas de ser e viver dos trabalhadores. No século XXI, marcado por profundas crises econômicas, políticas e sociais, o trabalho tomou outra configuração que o tornou mais fragmentado e precário. Nesse contexto se agudiza o trabalho informal, intermitente, precarizado e "flexível". As novas formas da organização do trabalho incluem exigências de práticas ancoradas na flexibilidade, multifuncionalidade, polivalência e em times de trabalho interdependentes. São desenvolvidos mecanismos de gestão pautados na pressão psicológica para o cumprimento de metas. Também se verificam, neste cenário atual, formas diversas de vínculos e condições de trabalho, jornadas laborais mais intensas e extensas, maior insegurança e vulnerabilidade (Antunes, 2018).

Essas transformações do trabalho tiveram consequências sobre as políticas públicas e a prática dos profissionais que lidam com o setor público. Especificamente no sistema educacional brasileiro, concretizou-se a implantação da Pedagogia Tecnicista entre as décadas de 1970 e 1980, cuja filosofia produtivista vinha sendo incentivada em outros setores da sociedade conforme o ideário neoliberal vigente. Toda uma maquinação organizacional que envolveu os trabalhadores de modo isolado e sistêmico foi necessária para se pôr em prática a busca pela eficiência funcional, o controle do ambiente e o manuseio tecnológico (Luckesi, 1994) a partir do pensamento racional, neutro e técnico - filosofia neoliberalista (Libâneo, 2001). Com ela, pretendia-se prescrever ao professor uma ação precisa e eficiente que oportunizasse o controle e a disciplina do comportamento do alunado em prol dos melhores resultados para o sistema (Saviani, 2013).

A racionalização nos moldes característicos da produção capitalista que foi utilizada nas escolas ocasionou um conflito aos docentes em face da discrepância entre o que se prescrevia e a realidade de sua prática profissional. Os professores se viram diante do paradoxo de ter que desempenhar suas funções tomando por base o ditame tecnicista de controle, limitação e objetivismo da ação, que se contrapunham à necessária flexibilidade subjetiva do ofício docente. Diante de tal contradição, o docente fica impedido de agir adequadamente de acordo com as necessidades do seu fazer e 
da mobilização de sua subjetividade. Assim, quando o enfrentamento adequado dos constrangimentos está bloqueado, o sofrimento no trabalho começa a aparecer.

Para Dejours (1992), esse fato não é de se estranhar, pois, quando a organização do trabalho se apresenta com rigidez ao trabalhador, dificulta o surgimento de estruturas que visam a manutenção e/ou eclosão de ações resistentes ao patológico. Embora o adoecimento relacionado ao trabalho já existisse antes dessa reestruturação produtiva, a literatura mostra que a busca pela eficiência produtiva por meio da mobilização da subjetividade do trabalhador trouxe efeitos irreparáveis ao humano, aumentando desenfreadamente as patologias relacionadas às vivências impedidas pelas organizações de trabalho (Clot, 2010; Dejours, 2011a).

É factível que historicamente o trabalhador que desempenha a atividade docente tem resistido às inúmeras investidas capitalistas quanto à adequação aos padrões neoliberais que a eles são atrelados (Libâneo, 2001; Saviani, 2013). Esse fato se intensifica quando se trata daqueles profissionais que lidam diretamente com a Educação Especial na perspectiva da Educação Inclusiva (Paisan, Mendes, \& Cia, 2017; Lopes \& Marquezine, 2012). Por essa razão, busca-se aqui compreender como esses profissionais desenvolvem sua atividade de trabalho em meio às dificuldades inerentes à tarefa. O trabalho que é prescrito para o funcionamento das salas de recursos multifuncionais (SRM) não condiz totalmente com o trabalho realizado, ou seja, existe um fosso entre aquilo que é externamente determinado e a realidade vivenciada pelos docentes nas SRM. O docente se vê então diante de uma situação de fracasso por não poder cumprir o que está prescrito. É afetivamente que o trabalhador enfrenta essa situação que lhe provoca sentimentos variados, porém, permite a experiência com a realidade e consigo mesmo, em uma situação de sofrimento que está na base da inteligência que incita o sujeito a agir sobre o mundo. Esse engajamento do trabalhador leva à mobilização subjetiva no trabalho que envolve esforço de inteligência para enfrentar os constrangimentos do trabalho, o esforço de encontrar a melhor forma de realizar o trabalho, esforço no processo de discussão para se definir o melhor modo de trabalhar, que demanda a cooperação na gestão da organização do trabalho (Dejours, 2012b).

Trabalhar no âmbito escolar na perspectiva da inclusão dos sujeitos com deficiências exige do trabalhador uma ação que ultrapassa a técnica (Sawaia, 2014); requer dele uma maior mobilização subjetiva a fim de aproximar o seu fazer daquilo que é prescrito pela legislação para o Atendimento Educacional Especializado (AEE), que envolve uma responsabilização individual e coletiva. A atividade docente desempenhada na SRM ultrapassa o espaço arquitetônico, expande-se por ações mais complexas que demandam instigar a comunidade escolar a refletir sobre o outro, sobre políticas públicas e, especialmente, sobre a dialética existente entre a inclusão e a exclusão (Paisan et al., 2017). Perpassa, pois, pela forma como se organiza e se gere o trabalho (Dejours, 2012b).

De acordo com a Psicodinâmica do Trabalho (PDT), a gestão laboral constitui o destino da mobilização subjetiva do trabalhador, já que o modo de gerir o trabalho se fundamenta pela organização. É na gestão do trabalho que se definem as tarefas, seus modos de exercício e as relações que se estabelecem em seu contorno para que haja o enfrentamento dos constrangimentos, das variabilidades do trabalho e da defasagem entre o prescrito e o real. Desse modo, os trabalhadores passam a se mobilizar subjetivamente estabelecendo estratégias individuais e coletivas com fins a dar consecução a sua atividade (Dejours, 2012b).

Nesses termos, é preciso que o sistema de ensino implemente uma organização do trabalho que possibilite a contribuição dos docentes no processo ensino-aprendizagem e valorize as diferenças existentes nas instituições educacionais de forma a atender às necessidades educativas de todos os alunos. Mas, como apresenta a literatura, essa não é uma incumbência exclusiva da escola, pois faz-se imprescindível a contribuição da comunidade. Dentre outros aspectos, esta responsabilização polarizada - escola e comunidade - tem intensamente demandado mobilização subjetiva dos trabalhadores das escolas (Neves, 1999).

A Política Nacional de Educação Especial na Perspectiva da Educação Inclusiva (Ministério da Educação [MEC], 2008) institucionalizou e legalizou a implantação das SRM nas escolas públicas de ensino regular a fim de concretizar a inclusão de crianças deficientes, com transtornos globais do desenvolvimento $^{1}$ e/ou altas habilidades/superdotação (Nota Técnica n. 11, 2010). Contudo, a atividade do AEE que

\footnotetext{
${ }^{1}$ Atualmente, pelo Manual Diagnóstico e Estatístico de Transtornos Mentais (American Psychiatric Association [APA], 2014), o Transtorno Global do Desenvolvimento (TGD) está incluso no Transtorno do Espectro Autista, juntamente com o Autismo, o Transtorno de Asperger, o Transtorno Desintegrativo da Infância e o Transtorno de Rett; assim passando a ser categorizado.
} 
nela é executada ultrapassa as prescrições impostas pela política apresentada. Sua prática é composta de variabilidades humanas e técnicas presentes nas escolas que muito requisitam a subjetividade humana (Paisan et al., 2017).

O AEE, por si só, não garante a integralidade da inclusão, pois não engloba a completude do sujeito que tem uma deficiência. A inclusão dele vai além de uma aceitabilidade na escola e da adequação de um plano de atendimento educacional; ela visa antes de tudo o respeito à cidadania, o que torna necessária a interligação dos diferentes contextos sociais. Precisa-se de uma rede pública que reúna as diversas competências para se efetivar a proposta. Ademais, o docente é um dos elementos da rede que deve se adequar às exigências do AEE, por meio de uma preparação subjetiva e técnica. $\mathrm{E}$ isso não é prescrito pela legislação (Paisan et al., 2017).

O AEE foi criado com o objetivo de desenvolver o aluno com deficiência em suas especificidades a partir de ações complementares ao ensino regular (Fávero, Pantoja, \& Mantoan, 2007). Segundo a prescrição de sua prática, tem a função de concretizar a inclusão apresentando um conjunto de atividades e recursos pedagógicos e de acessibilidade organizados institucionalmente para garantir a eliminação das barreiras que obstruem o processo de escolarização de alunos com deficiências, transtornos globais do desenvolvimento, altas habilidades ou superdotação (Resolução n. 4, 2009). Para tal, muito se espera do docente na SRM a fim de colocar em prática suas diretrizes.

Portanto, o presente artigo tem por objetivo compreender a relação entre o que é prescrito na legislação brasileira para o desenvolvimento do trabalho nas SRM e o que de fato se consuma em um município do Nordeste brasileiro, além de mostrar como se mobilizam subjetivamente as professoras desse local para que seja efetivado o AEE frente às condições e organização do trabalho que lhes são impostas.

\section{Sobre o método}

O presente estudo se fundamentou nos preceitos da PDT, que considera que os fatos não existem em si, mas devem ser extraídos de uma dinâmica intersubjetiva mediada pela linguagem (Dejours, 2011a). Caracteriza-se para além de um estudo teórico, pois se apresenta como uma ação propícia à conscientização humana, a partir da escuta atenta da vivência subjetiva frente à realidade da organização do trabalho adotada (Louzada \& Oliveira, 2013). Trata-se, portanto, de uma pesquisa qualitativa quanto à abordagem e explicativa quanto aos objetivos (Gil, 2002).

A pesquisa respeitou todas as etapas pertinentes aos procedimentos éticos em pesquisas com seres humanos pautados pela Resolução de n. 510/16 do Conselho Nacional de Saúde (CNS) (Resolução n. $510,2016)$; só foi efetivada em prática após autorização do comitê de ética de uma instituição de ensino superior local somada às autorizações institucionais e assinatura dos Termos de Consentimento Livre e Esclarecido (TCLE) das participantes. Realizou-se, pois, em 8 SRM inseridas nas escolas de um município do Nordeste brasileiro, onde foram feitas observações não participantes do trabalho por meio de visitas institucionais. As observações proporcionaram uma primeira visão do trabalho das docentes das SRM a partir do olhar dos pesquisadores sobre as tarefas e relatos das professoras acerca de sua atividade. Essa técnica permitiu confrontar o que a legislação prescreve para o desempenho da tarefa do AEE com o que de fato se apresenta nessa atividade. Foram realizadas 2 visitas institucionais em cada escola, que serão chamadas ao longo da pesquisa por $\mathrm{E}_{1}, \mathrm{E}_{2}, \mathrm{E}_{3}, \mathrm{E}_{4}, \mathrm{E}_{5}, \mathrm{E}_{6}, \mathrm{E}_{7}$ e $E_{8}$. Utilizou-se de fichas de observação para registro das impressões obtidas nas visitas que serviram para a construção posterior de diários de campo e roteiro de discussão. A pesquisa contou ainda com a participação de 4 professoras nos encontros coletivos de discussão propostos pelos pesquisadores - denominadas ao longo do estudo de $\mathrm{P}_{1}, \mathrm{P}_{2}, \mathrm{P}_{3}$ e $\mathrm{P}_{4}$. Ao todo, obteve-se a participação de 12 professoras, sendo 8 delas na etapa da observação institucional e 4 na etapa dos grupos coletivos de discussão. Caracterizaram-se por um perfil exclusivamente feminino, graduado, especializado em campos de conhecimento afins ao AEE, com vínculo efetivo com o município e com tempo de serviço na atividade nas SRM entre 2 e 11 anos. Como acordado com as docentes, foram realizados 3 encontros coletivos de discussão, que ocorreram em uma sala disposta no Centro de Tecnologia (CTE) do município e tiveram duração média de cerca de $2 \mathrm{~h}$ (duas horas) cada. Neles se efetivou um espaço para o diálogo entre as professoras por suas vivências subjetivas, instigado por aspectos observados pelos pesquisadores nas visitas institucionais, por meio de um roteiro de discussão sobre os seguintes temas: organização de trabalho; trabalho prescrito e real; condições de trabalho; coletivos de trabalho; sofrimento 
no trabalho; e reconhecimento. Os dados das observações do trabalho e dos dois primeiros encontros de discussão coletiva foram analisados à luz da teoria da PDT e geraram relatórios apresentados para as docentes para validação e/ou refutação no terceiro e último encontro coletivo de discussão. As professoras puderam fazer colocações, alterações, discordâncias e/ou concordâncias com o material apresentado. O resultado deste último encontro gerou o relatório final e a conclusão da pesquisa.

\section{Resultados e Discussão}

Baseados nos conceitos apresentados pela PDT, para apresentarmos e discutirmos parte dos dados encontrados ao longo da pesquisa, utilizaremos duas categorias analíticas que serão denominadas: Trabalho prescrito e trabalho real; e Gestão do trabalho para o AEE.

\section{Trabalho prescrito e trabalho real}

De acordo com a PDT, o trabalho não se constitui em sua totalidade com o seu planejamento externo, mas é marcado por contingências técnicas e pessoais originadas pelas práticas cotidianas. Efetiva-se por variabilidades e constrangimentos diversos pelos quais exige do trabalhador uma mobilização subjetiva para a construção das relações sociais com fins na realização de uma tarefa (Louzada \& Oliveira, 2013). Configura-se, pois, para além de suas prescrições. É a caracterização própria do modo pelo qual o sujeito trabalhador se engaja com outros para resistir às mais diversas variabilidades encontradas na realidade do trabalho. Por isso, não se resume a uma pura ação instrumental, e sim ao engajamento das personalidades existentes no mundo laborativo hierarquizado, para a formação identitária do sujeito de modo individual e social frente aos constrangimentos nele presentes (Dejours, 2012a). Portanto, o que é prescrito no mundo do trabalho não é em sua totalidade o real.

Nesse sentido, na pesquisa realizada nas escolas que possuem SRM foi possível perceber a distância entre o que se previa para o funcionamento desse tipo de dispositivo escolar, o que as professoras encontram em seu cotidiano e o que conseguem fazer. Conforme preveem as Diretrizes NacionaisparaaEducação Especial na Educação Básica a partir da Resolução n. 2/2001 do Conselho Nacional de Educação (CNE), a realização do Atendimento Educacional Especializado (AEE) nas Salas de Recursos Multifuncionais (SRM) deve ocorrer em horário oposto ao atendimento regular, a fim de assegurar aos alunos que apresentam deficiências as condições necessárias para uma educação de qualidade (MEC, 2001). Contudo, na prática, o contraturno não funciona como proposto na legislação. Conforme os dados da pesquisa, não há homogeneidade no funcionamento das SRM no município nordestino pesquisado, na medida em que a variabilidade do contraturno é uma marca do trabalho nas escolas.

Embora exista a norma legal do contraturno, várias foram as questões impeditivas apresentadas nos dados para que ela seja cumprida. "Muitos pais e/ ou responsáveis se mostram resistentes por não terem como retornar à escola no outro horário por ser custoso financeiramente ou por dificuldades de acesso do trajeto pelas próprias características das crianças, como por exemplo, as cadeirantes" (depoimento das participantes $\mathrm{P}_{2}$ e $\mathrm{P}_{3}$ no encontro de discussão). Outros relataram "empecilhos provocados pela medicação consumida por parte das crianças, deixando-as sonolentas" (diálogo com as docentes após observação das $\mathrm{E}_{1} \mathrm{e}_{7}$ ). Alguns outros citaram "não ter quem as retornassem à escola por questões de trabalho dos adultos familiares" (diálogo com as docentes após observação das $\mathrm{E}_{4}, \mathrm{E}_{6}$ e $\mathrm{E}_{8}$ ). Como também se relatou "motivos boicotadores frente a ser o mesmo horário de outros atendimentos, de caráter clínico, prestados às crianças" (fala de $\mathrm{P}_{1}, \mathrm{P}_{3}$ e $\mathrm{P}_{4}$ no encontro de discussão).

Sabendo de algumas irregularidades no funcionamento das SRM quanto às prescrições legais, inclusive frente ao funcionamento do contraturno, o Ministério Público do Estado visitou as escolas e obrigou, por meio de um TAC (Termo de Ajustamento de Conduta), que a Secretaria de Educação Municipal (Seduc) fizesse ajustes compulsórios de vários aspectos do funcionamento desses espaços. Uma destas mudanças foi a adoção de uma nova norma com o intuito de fazer o AEE atuar em horário oposto ao da sala de aula regular. Para tanto, a Secretaria Municipal criou, inicialmente, um documento que os pais e/ou responsáveis teriam que assinar comprovando que as crianças passariam a ser atendidas nestes termos, responsabilizando a família por levar a criança ao AEE em horário diferente do regular. O Ministério Público também determinou que, posteriormente, a Seduc lançasse uma nova resolução apresentando todas as diretrizes sobre o funcionamento das SRM, o que se concretizou com a Resolução n. 2/2019 de abril de 2019, 
do Conselho Municipal de Educação (CME). A recente prescrição sobre o documento do contraturno, ao invés de regularizar o funcionamento previsto em lei, desencadeou novas problemáticas a seguir discriminadas. $\mathrm{O}$ documento que obrigava os pais a assinarem a frequência dos filhos no contraturno se apresentou como um novo constrangimento atrelado à atividade docente. Ele conturbou a boa relação que as professoras já haviam desenvolvido com os pais e/ou responsáveis. Pois, enquanto prescrição, quando estes se recusassem a assinar o termo de responsabilidade, deveriam ser notificados à Seduc e, posteriormente, ao Conselho Tutelar por negligência ao atendimento. Como as professoras são as profissionais que estabelecem o primeiro contato com os familiares, elas recebem todo o impacto negativo das insatisfações das famílias de seus alunos. Elementos como esses que estão vinculados ao trabalho nas SRM têm potencializado a sobrecarga mental docente, gerando gradualmente emoções deletérias ao fazer profissional.

"A relação com a família é muito boa. Mas, esse documento que temos que colocar os pais para assinar para irem no contraturno tem prejudicado isso" (fala de $\mathrm{P}_{4}$ no encontro coletivo de discussão). "Este documento da SEDUC do contraturno tem pressionado as famílias" (fala de $\mathrm{P}_{2}$ no encontro coletivo de discussão). "O que tem me angustiado é o contraturno, pois a relação com os pais é muito boa e esse documento está atrapalhando isso" (fala de $\mathrm{P}_{1}$ no encontro coletivo de discussão).

Essa medida adotada pela Secretaria de Educação para adequação judicial em cumprimento à prescrição do MEC exigiu das professoras um uso ainda mais intenso de sua inteligência prática na atividade laboral. Lançam artimanhas para que os pais e/ou responsáveis assinem o documento e não se indisponham com elas. Esse fazer não é simples, pois não envolve somente um ato mecânico de assinatura, mas relações pessoais que são constituídas dificultosamente com as famílias. As reclamações das docentes de sobrecarga mental decorrente da lida com os pais em relação a esse documento são, portanto, procedentes.

Conforme afirma Dejours (2011b), em uma organização de trabalho, o que está prescrito não é suficiente. No real do trabalho, surgem descobertas, engenhosidades e inovações advindas de interpretações sobre o prescrito. Ele passa a ser conhecido por quem trabalha na sua resistência ao saber-fazer, aos procedimentos, às prescrições, à habilidade técnica e às impostações (Dejours, 2012a). Nesse sentido, nas observações do trabalho destas docentes e nos encontros de discussão, pôde-se perceber divergências claras entre o que era estabelecido para se fazer e o que acontecia na realidade, como, por exemplo, o próprio público-alvo.

De acordo com a Resolução n. 4/2009, que explicita as diretrizes operacionais para os docentes na Educação Básica na modalidade Educação Especial, o AEE, por meio de recursos de acessibilidade e pedagógicos organizados institucionalmente, deve atender aos alunos com deficiências (que causam impedimentos a longo prazo de natureza física, intelectual, mental ou sensorial), transtornos globais do desenvolvimento, altas habilidades e/ou superdotação (Resolução n. 4, 2009) na perspectiva da inclusão. Entretanto, o que se verificou na realidade do trabalho foi que, em algumas escolas, outros alunos que não se encaixam na prescrição também recebem o atendimento.

Em determinadas situações, o AEE recebe um aluno encaminhado pelo professor da escola ou creche que não se enquadra na caracterização contida na lei. Mesmo assim, as professoras acolhem os alunos e fazem todo o procedimento para estabelecer se a criança se enquadra em alguma patologia que deve ser acompanhada pelo AEE conforme o prescrito. Quando concluem que o problema da criança é um tipo de transtorno que não compete ao AEE acompanhar, orienta os pais e/ou responsáveis a procurarem outro tipo de serviço clínico, como o psicológico.

"Quando eu comecei a trabalhar com o AEE atendia às deficiências e às dificuldades de aprendizagem, hoje já vamos impondo: meu aluno é esse?" - referindo-se às deficiências (fala de $\mathrm{P}_{4}$ no encontro coletivo de discussão). "Também faço atendimentos a diversas crianças por outros motivos que são a pedido das professoras das salas regulares: por não se comportar bem, por não querer desenvolver as atividades etc." (fala de $\mathrm{P}_{1}$ no encontro coletivo de discussão).

Como demonstrado nas falas acima, o tempo de desempenho funcional na atividade do AEE tem provocado as professoras a desenvolverem artimanhas de enfrentamento dos constrangimentos da tarefa. O uso da inteligência prática se faz presente de forma cotidiana. Embora já existisse a prescrição para o público a ser atendido na SRM desde 2008, quando da implantação da política, conforme as falas acima, ainda se percebe muitos ajustes. Porém, parte das professoras demonstraram buscar, a partir de sua experiência com os tipos de deficiência, estabelecer limites em relação aos alunos que não cumprem os requisitos para frequentar as salas. 
Além dessa divergência no real do trabalho quanto ao público-alvo a ser recebido no AEE, também ficou evidente que há esforço, por parte das docentes, para adequação às prescrições apresentadas pela Política Nacional de Educação Especial na Perspectiva da Educação Inclusiva (MEC, 2008) e todos os outros documentos referenciais adjacentes. Esse esforço mostra toda a mobilização subjetiva que é requerida na atividade com a inclusão para dar conta das variabilidades que acontecem na jornada de trabalho. A professora deve usar sua inteligência prática para que os familiares não compreendam erroneamente que não querem atender suas crianças, bem como para contribuir com os outros docentes da instituição quanto ao esclarecimento do público legal da SRM. É um esforço mental necessariamente engendrado pelas profissionais para dar consecução a sua atividade.

Ao mesmo tempo em que há esse desgaste mental para argumentar o porquê não se vai atender a determinados grupos de alunos distintos da regra, por outro lado, a busca pelo cumprimento da norma é uma forma de evitar a sobrecarga de trabalho e estabelecer os parâmetros para o bom desenvolvimento de seu fazer. Nesse sentido, as professoras já conseguem estabelecer parâmetros para aceitar seu público-alvo legal. Conseguem estabelecer regras de trabalho que evitam mais trabalho para se aproximar de um diagnóstico, haja vista não ser de sua competência, pois desempenham atividade pedagógica e não clínica. Como diz a segunda professora participante $\left(\mathrm{P}_{2}\right)$ : “hoje já vamos impondo?", isto é, sua experiência já permite tomar uma decisão sobre seu público-alvo sem ter que se envolver de modo técnico e emocional com cada caso.

Na pesquisa também encontramos discrepância entre o prescrito e o real quanto à estrutura física das SRM. Segundo o Documento Orientador do Programa de Implantação das Salas de Recursos Multifuncionais (MEC, 2012), elas devem ser constituídas de um espaço que apresente condições de acessibilidade e materiais pedagógicos adequados para o desenvolvimento do AEE.

Verificou-se nas observações do trabalho nas escolas que as SRM implantadas na cidade também não cumprem, em sua totalidade, o que foi previsto da legislação de implantação das salas. Enquanto algumas escolas se apresentam adequadas às normas nacionais instituídas para sua implantação e funcionamento, outras estão defasadas em relação às normas preestabelecidas, fato que provocou, em face das dificuldades em cumprir com as exigências do TAC, a desativação de 4 SRM no início de 2019. A defasagem foi explicitada nas falas das professoras que desenvolvem o AEE.

"Sala ampla, adaptada para o AEE, com parte do mobiliário original destinado pelo MEC e outros adquiridos por meio de doação da própria escola, da professora e de outros. Bem iluminada e ventilada" (observação da $\mathrm{E}_{1}$ ). "Sala pequena, acoplada ao almoxarifado onde se guarda muito material da escola. Vizinha à sala dos professores, de onde vem muitas interferências" (observação da $\mathrm{E}_{2}$ ). "Sala ampla, mas com vários materiais e imobiliários improvisados. Muito material confeccionado, bastante livros, poucos recursos tecnológicos, sem a presença de qualquer imobiliário destinado pelo MEC, muitos recursos trazidos e arcados pela própria professora" (observação da $\mathrm{E}_{3}$ ). "Sala bem ampla e específica para o AEE, com boa ventilação e iluminação. Tem proximidade com as salas regulares. E apresenta bastante material confeccionado pela professora e pais, além do mobiliário trazido pelo MEC" (observação da $\mathrm{E}_{4}$ ).

Como verifica-se na descrição das observações realizadas nas SRM, a variabilidade estrutural no município é grande e muitas delas dificultam o desempenho da atividade. Por isso, como forma de buscar ajustes frente a essas questões, parte das docentes demonstraram desenvolver estratégias diversas para facilitar o trabalho. Mesmo contrariamente à legislação, algumas das SRM eram situadas em locais de grande interferência externa, dividindo espaço com almoxarifado escolar ou sala de leitura, fato potencialmente impeditivo da atividade. Em mais um aspecto, as docentes passaram a demonstrar sua capacidade inventiva para desempenhar a função em meio ao real do trabalho. Muitas delas sobrecarregavam-se mentalmente para buscar acordos com a gestão escolar para modificação local da instalação da sala e/ou dos serviços nos espaços ofertados (como aconteceu nas $\mathrm{E}_{5} \mathrm{e} \mathrm{E}_{7}$ ). Contudo, nem sempre conseguiam e muitas das professoras deviam exercer a função em meio a ruídos, amontoados de materiais e entrada e saída de outros profissionais do espaço de ensino-aprendizagem.

Essa mesma situação acontece quanto ao mobiliário e materiais pedagógicos, pois muitas das SRM não demonstraram ter tais recursos conforme a prescrição legal para o funcionamento. Há mais um hiato entre o prescrito e o real. Para dar conta dessa defasagem, as professoras passam a se mobilizar de forma 
subjetiva individual e coletiva desenvolvendo técnicas diversas que lhes possibilitem a aquisição dos materiais, como: requisição via ofício à Seduc de atualização do mobiliário e recursos pedagógicos; o custeamento próprio de materiais de trabalho; a promoção de campanhas de captação de doações com amigos e familiares; a elaboração de brechós para a venda de roupas para o angariamento de recursos financeiros; a promoção de oficinas junto aos pais e/ou responsáveis para a confecção de tecnologias assistivas; dentre outras. Conforme se percebe, as docentes se mobilizam subjetivamente fazendo uso de sua capacidade inventiva o tempo todo para lidar com os constrangimentos; nesse aspecto, buscam mobilizar o coletivo para o desenvolvimento da atividade do AEE.

A discrepância existente entre o prescrito e o real é inegavelmente presente nas SRM, porém, como afirma a PDT, isso será concebível e presente de modo constante, pois acontece mesmo quando se consegue instituir uma organização de trabalho rigorosa com as indicações e explicitações dos procedimentos a serem realizados em dada tarefa (Molinier, 2013). No AEE do município nordestino pesquisado, mesmo que haja prescrições apresentadas via MEC, TAC e Seduc, o real ainda se comprova distante do que é prescrito e, possivelmente, continuará a ser, pois, segundo Molinier (2013), não há organização prescrita do trabalho que seja infalível; haverá zonas de sombra nas quais surgem situações que não são previstas, que escapam aos procedimentos anteriormente repertoriados.

A atividade que as docentes encetam em seu trabalho para dar conta da organização prescrita do trabalho permite que possam ser criativas, contribuir com seu saber-fazer para o melhor desenvolvimento de seu trabalho, criar situações de trocas entre seus pares e sua clientela. Ser ativas no trabalho permite transformar as situações de sofrimento que advêm da sobrecarga mental e que poderiam em longo prazo causar adoecimento que as impossibilitasse de trabalhar. Fazer de forma criativa permite-as continuar trabalhando. Ao contrário, não lutar para transformar as situações que geram sofrimento e demandam seu esforço para dar consecução ao trabalho pode perpetuar as normas exteriores da organização do trabalho.

\section{Gestão do trabalho para o AEE}

Por meio da mobilização subjetiva, o trabalhador se põe diante dos desafios constituintes da organização do trabalho, usa sua inteligência e partilha com seu coletivo o diálogo sobre os modos de arbitragem frente às contradições presentes no ambiente (Dejours, 2011b). Ou seja, é na gestão do trabalho que são delineadas as ações individuais e coletivas para enfrentamento do real do trabalho (Giongo, Monteiro, \& Sobrosa, 2015). Quando o trabalhador se ocupa de uma dada tarefa, ele espontaneamente busca organizá-la em uma ordem, em sequências de gestos e utilização de instrumentos por ele escolhidos, para manifestar, por meio do uso da inteligência, o comprometimento com o trabalho e a formação identitária (Dejours, 1992). Assim, para a PDT, uma mesma tarefa, quando executada por diferentes trabalhadores, pode sim ser realizada segundo protocolos divergentes, conforme será verificado nos dados da pesquisa.

De acordo com a Nota Técnica n. 11/2010 (2010), a organização da prática pedagógica na SRM deve acontecer a fim de assegurar aos alunos com deficiências, transtornos globais do desenvolvimento, altas habilidades e superdotação, o direito à educação plena e participativa, em igualdade com os demais alunos. Para isso, requisita que seja elaborado um plano de AEE a fim de que a prática esteja articulada às habilidades e necessidades educacionais específicas dos alunos, bem como um planejamento de oferta do atendimento de forma individual e/ou grupal. O professor é quem organiza seu cronograma de atendimentos de acordo com as características dos problemas apresentados pelo alunado. Entretanto, o real do trabalho demonstra que a carga horária é sempre extrapolada em face de diversas variabilidades como as características da clientela.

Conforme descrito no trecho do relato da participante $\mathrm{P}_{1}$ do encontro coletivo de discussão, "somos nós quem montamos os horários. É permitido que tenhamos um espaço entre os atendimentos, mas as crianças gostam de estar na SRM, então tem hora que a sala está cheia". Segundo a participante $\mathrm{P}_{2}$ é comum haver "atropelamentos" dos horários dos professores para lanche, água ou ida ao banheiro, porque "as mães não vêm pegar no horário marcado, e nós precisamos ficar com o aluno para não o deixar solto na escola". A participante $\mathrm{P}_{3}$ afirma que "Tem crianças que chegam antes do horário marcado e vêm de muito longe, então é preciso atender. Não dá para deixar o aluno fora da sala para que a gente organize o ambiente e material para um próximo atendimento". E a participante $\mathrm{P}_{4}$ diz que "acontece muito de as mães dos alunos trazerem seus filhos antes e vim pegar depois do horário marcado. Se eu estiver livre, eu pego". 
As falas mostram que o atendimento do aluno antecipado ou prolongado quanto ao horário previamente estabelecido se apresenta como um prolongamento da jornada de trabalho. São situações em que as professoras têm que usar inteligência da prática para abarcar o volume de trabalho. Crianças que chegam antes da hora por morar longe, mães que não chegam no horário para pegar seu filho acarretam que as professoras extrapolem suas atribuições e resolvam o que fazer. Muitas vezes, não há tempo de devidamente cumprir o que foi planejado para uma jornada de trabalho em face das demandas que os alunos trazem nesse período. A professora, nesses casos, tem que se mobilizar para atender às crianças e fazer as tarefas de continuidade do fazer no horário posterior. O tempo de descanso que a docente teria entre uma aula e outra, período importante para ela se restabelecer, ajustar as ideias e os materiais, ter contato com colegas, se esvai porque deve ficar em sala de aula para acompanhar as crianças que não saem do recinto. Tudo isso pode levar a uma sobrecarga física e mental considerável para as professoras.

Também se verifica, conforme as falas das participantes, que a gestão desenvolvida no trabalho com o AEE é muito particularizada a cada SRM, pois cada professor adequa o modus operandi de forma bem específica para lidar com os constrangimentos atrelados a sua tarefa. Entretanto, existem ações que remetem a regras de trabalho do coletivo das professoras que atuam nesses espaços, mesmo em escolas diferentes - como, por exemplo, a mencionada priorização dos alunos no atendimento antecipado ou prolongado quanto ao horário previamente estabelecido, devido ao requerimento de que na SRM haja apenas um profissional em exercício por turno.

A atividade delas cobre uma variada gama de nuances que não é visível para a maioria dos que trabalham na escola. O que se espera da professora é que atenda aos alunos. Em algumas escolas verificou-se que as professoras aproveitam o tempo em que algum aluno falta para cumprir outras tarefas como as questões burocráticas do seu trabalho. Segundo afirma a P2 do encontro coletivo de discussão, "antes quando o aluno faltava, eu substituía por outro. Hoje, não faço mais, vou resolver as questões burocráticas, como os registros nos diários, por exemplo". Essa fala foi corroborada pela participante P4: "quando o aluno do contraturno não vem ao atendimento no horário marcado, eu não atendo outro, pego este momento para resolver a burocracia: diários, planejamento. Embora seja cobrada pelos professores para atender outros alunos, não faço mais isso!".

Verificou-se que as professoras, por sua experiência, adotam astuciosamente formas de lidar com as demandas do trabalho que são uma sobrecarga. O preenchimento de formulários toma um tempo grande da atividade delas. Para não terem que fazê-lo sempre fora do horário de trabalho estabelecido, em casa, por exemplo, elas adotaram esta estratégia de preencher a documentação nos horários em que não têm aluno para atender. Pois, também em conformidade com o TAC, foi-lhes retirado o período que utilizavam para dar conta destas ações: a sexta-feira era um dia reservado exclusivamente para os atos burocráticos. A Seduc justificou essa medida dizendo ser suficiente o momento de "hora departamental" adotado por cada unidade escolar em cumprimento à carga horária docente de 30 horas semanais para recebimento do piso salarial nacional. Ou seja, uma medida dos gestores da educação sobrepuja as regras de trabalho estabelecidas pelas professoras, que devem se ajustar à nova norma. Os dados mostram, contudo, que mesmo que as professoras preenchessem os documentos na escola, não conseguiam dar conta de seu volume e tinham que realizar essa tarefa fora do local de trabalho. Ficava inviável para as docentes preencher os documentos entre os atendimentos, tampouco em sua completude nos "horários departamentais", conforme já apresentado em suas falas.

Aproveitar o tempo da falta de um aluno, não para descansar, mas para cumprir a burocracia de sua tarefa, muitas vezes não é bem compreendido por professores de outros setores da escola. As docentes do AEE falam que alguns colegas de trabalho que não lidam com as SRM não conseguem abarcar a complexidade da atividade nesse local. Outros docentes não compreendem porque elas realizam outras tarefas mesmo que não estejam trabalhando diretamente com alunos. Essa ação adotada por elas é uma estratégia direta de resistência ante os constrangimentos do trabalho para diminuir a sobrecarga presente do AEE.

Dentre as diversas atribuições das professoras das SRM, tem-se o planejamento do atendimento dos alunos, a construção do plano de atendimento educacional especializado MEC, 2008). Existe o planejamento que traça os objetivos e as metas anuais e os planejamentos circunstanciais, que são realizados em períodos diferentes e dependem da demanda. Em 
decorrência da retirada da sexta-feira como dia reservado à realização dessa ação pelas docentes verifica-se na prática que a gestão do planejamento ocorre segundo as especificidades de cada escola e da clientela. Assim também ocorre o estabelecimento cronológico do atendimento aos alunos.

As docentes usam de sua subjetividade, mostram suas singularidades na atividade de trabalho. No planejamento, enquanto algumas professoras constroem o plano anual e quinzenal (observação das $\mathrm{E}_{1} \mathrm{eE}_{3}$ ), outras preferem construir o documento de modo anual e semanal (observação das $\mathrm{E}_{2}, \mathrm{E}_{5}$ e $\mathrm{E}_{3}$ ). As singularidades também se expressam quanto ao tempo que usam para atender os alunos. Algumas das professoras realizam o atendimento com duração de $1 \mathrm{~h} 30 \mathrm{~m}$ (observação da $\mathrm{E}_{1}$ ); outras preferem desenvolver o serviço com variância de 50, 40 ou 30 minutos (observação das $\mathrm{E}_{5}$ e $\mathrm{E}_{6}$ ). Elas justificam as variações de tempo como acomodações para atender a mais alunos e cumprir outra norma estabelecida pelo TAC e exigida pela Seduc: precisam atender o mínimo de 15 alunos por turno.

Como é possível verificar, embora a atividade do AEE possibilite autonomia às professoras para a construção de seu plano de atendimento educacional e organização dos cronogramas - um aspecto positivo desta tarefa -, a restrição quanto às condições para quando e como eles são feitos tem provocado intensos desgastes físicos e mentais às trabalhadoras e a situação tem levado várias delas a um estado mental desgastante. Não suportando mais contribuir com a organização do trabalho em um contexto de cobranças e controles e para não sucumbir completamente ao adoecimento mental, as docentes passaram a requisitar à Seduc sua saída da SRM na qual desempenhavam a atividade do AEE para uma sala de aula regular. Muitas delas passaram a se sentir sobrecarregadas quanto ao cumprimento das exigências burocráticas do trabalho do magistério (planos, diários, termos de responsabilidade aos pais etc.) após a Secretaria Municipal suprimir o dia semanal dedicado especificamente a esse fim, bem como estabelecido um número mínimo de alunos a serem atendidos. Portanto, verifica-se a produção de um sofrimento numa linha mais patogênica no trabalho das docentes das SRM, a ponto de quererem sair dessa função.

Como afirma a participante $\mathrm{P}_{3}$, "estou prestes a deixar a SRM e ir para a sala regular, apesar de amar o AEE, hoje há muitas questões burocráticas, o AEE se tornou uma função de preencher papel?'. Há sofrimento instalado no fazer dessas docentes. Como os dados demonstram, as professoras cotidianamente usam sua criatividade para poderem dar conta das exigências que, como visto, são constrangedoras do fazer docente e levam a sobrecarga mental. Se não existissem a autonomia e as regras de trabalho sedimentadas coletivamente, talvez muitas dessas trabalhadoras estariam propensas a sair da SRM. A elaboração das estratégias na atividade, como a diminuição do tempo de atendimento de cada aluno para aumentar a quantidade atendida e as adequações de planejamento semanais, quinzenais e/ou mensais, evidenciam o sofrimento criativo dessas trabalhadoras. Sofrimento este que instiga a resistência do sujeito quanto ao risco de desregulação intra e interpsíquica (Neves, Seligmann-Silva, \& Athayde, 2004). Mesmo imersas em uma organização de trabalho que apresenta impedimentos ao fazer, elas são ativas, fazem o trabalho de forma criativa (Dejours, Abdoucheli, \& Jayet, 1994).

Outro aspecto da organização do trabalho que a pesquisa levantou em relação às docentes das SRM é que seus momentos dos intervalos são diferenciados dos outros professores. Por isso, não conseguem compartilhar as salas regulares dos espaços de convivência social dos professores em geral. O espaço do intervalo entre as aulas é um momento fundamental para que os professores da escola, de modo geral, possam conversar e descansar do contato com os alunos, afastando-se das tarefas. Segundo Dejours (2012b), é o coletivo quem vincula o subjetivo com o social, é a partir dele que se interligam a inteligência, a habilidade e a engenhosidade. Contudo, o que se viu em algumas escolas, o que seria um momento de repouso para as docentes das SRM na sala de professores passa a ser mais uma sobrecarga mental. As professoras participantes da pesquisa pontuaram que o horário do intervalo escolar não lhes permite o descanso necessário para retomada à sala de aula. Conforme afirma a participante $\mathrm{P}_{2}$ " por regra da direção, muitos alunos ficam de castigo na sala dos professores na hora do intervalo". Essa medida tomada pela gestão escolar tem, em muitas escolas, boicotado o espaço de diálogo entre os profissionais nos intervalos e trazido mais uma atribuição para os docentes que implicitamente ficam responsáveis por prestar atenção aos alunos. Consequentemente, a presença dos alunos não permite que as professoras conversem entre si e elas acabam se isolando; como afirma a participante $\mathrm{P}_{2}$,"o intervalo é sagrado, mas fica cada professor no seu WhatsApp até tocar". 
Esse modo de gerir o trabalho, por determinação dos dirigentes escolares, tem sido experienciado como empecilho ao viver junto das docentes, aspecto fundamental da constituição do sujeito em seu trabalho (Dejours, 2012b). A medida de colocar as crianças de castigo na sala dos professores é como uma punição para as docentes, pois tira a possibilidade de poderem conversar sobre sua vida, sobre seus dramas, sobre seus ganhos. Esse momento tem se tornado, assim, de sobrecarga, e não de descarga. As professoras reconhecem a importância desse espaço e explicitam que há uma perda em não ser possível partilharem esse momento com os colegas de trabalho.

O encontro com os outros professores das salas regulares na hora do intervalo é muito importante, mas é como se nós do AEE estivéssemos isoladas na escola. Há uma perda para nós por nem todos estarem no mesmo intervalo por conta das características da escola em ter fundamental 1 e 2 . Os alunos grandes não recreiam no mesmo tempo dos pequenos, com isso, há uma separação dos professores. Quando não se reúne todo mundo, há uma perda para a escola. Sinto falta quando não vou, perco as coisas. As brincadeiras entre nós tornam o ambiente prazeroso (depoimento de $\mathrm{P}_{3}$ no encontro coletivo de discussão).

Para Dejours (2012b), os encontros nos espaços informais são imprescindíveis, pois neles ocorre a mobilização da inteligência e da subjetividade, a contribuição em prol da produção, a imbricação dos sujeitos quanto à vontade de conjurar a violência do trabalho a partir dos acordos normativos entre os participantes.

Embora a maioria das escolas pesquisadas seja gestada nos moldes citados anteriormente, também foram encontradas outras que incentivam o trabalho coletivo. A participante $\mathrm{P}_{1}$ relatou outra realidade na escola em que trabalha. Confirma a importância do momento do intervalo e da possibilidade de se encontrar com seus pares. Ela diz contar na escola com uma equipe de apoio que fica observando as crianças no intervalo, bem como explicita que nesta escola a inclusão ocorre também no recreio quando as crianças brincam juntas.

Conforme as falas das participantes, a variabilidade é presente nas escolas. Os modos de gestão encontrados pelas professoras mostram que ao lidarem com os diversos constrangimentos da atividade do AEE, também são provocadas a vivenciar os sofrimentos atrelados à tarefa. Conforme Dejours et al. (1994), isso é inevitável, pois, naturalmente o sofrimento pertence à singularidade de cada sujeito. Quando atrelado ao trabalho, ele repercute ao entrar em uma relação complexa existente em sua organização. Assim, não há como subtraí-lo das atividades laborativas. Ao poder ser transfigurado em criatividade, provoca contribuições benéficas à identidade do sujeito expressadas por sua ação a partir da intensificação das formas de resistência aos fatores de desestabilização psíquica e somática. Contudo, quando todas as medidas de liberdade de transformação, de gestão e de aperfeiçoamento se esgotam, começa a se configurar em patogênico, descompensando o aparelho mental e o equilíbrio psíquico do sujeito.

Os dados da pesquisa mostraram que as professoras das SRM adotam diferentes modos de gestão individual e coletiva do trabalho ao lidarem com a ampla gama de variabilidade presente na tarefa do AEE, como: busca por visibilidade do trabalho frente ao coletivo, inventividade para obtenção de recursos pedagógicos e estruturais para a sala, efetividade em parcerias para busca do diagnóstico das crianças por especialistas, dentre outros. Portanto, a mobilização subjetiva das docentes demonstra quão complexa é a atividade do AEE, que muitas vezes não é compreendida em sua completude por boa parte dos profissionais das escolas. Como afirmou a participante $\mathrm{P}_{2}$ no encontro de discussão, "Já me determinei que no próximo ano, no primeiro planejamento, quer queiram ou quer não, vão ter que me dá tempo para apresentar os resultados estatísticos provando os avanços dos alunos que atendo". Essa professora quer mostrar, assim, como é a atividade do AEE, ou seja, quer explicitar para toda escola as nuances, especificidades, variabilidades e constrangimentos que envolve o fazer do AEE. Com os resultados, quer mostrar o trabalhar que é constituído de um conjunto de situações que acontecem no trabalho mas que muitas vezes as pessoas não percebem ou não conseguem enxergar. O que quer essa docente é mostrar o quão enigmático e complexo é o trabalho do AEE.

Como o AEE desenvolve um trabalho diferenciado das salas de aula regular, muitas vezes os outros professores fazem críticas ao que eles acham que seria a atividade nas SRM. Alguns acham que o trabalho do AEE é leve, ou seja, com poucas exigências. Daí decorre o interesse da participante $\mathrm{P}_{2}$ em trazer à tona como de fato é a atividade na sala de recursos 
multifuncionais, ou seja, aquilo que verdadeiramente se faz nesse espaço. A participante $\mathrm{P}_{2}$ diz que "não existe respeito para com o $A E E^{\prime}$, pois percebe que falta, por parte dos componentes das escolas visitadas, compreender como é o real do trabalho na SRM.

"Muitas são as estratégias utilizadas para dar conta da atividade do AEE. Os precários recursos das SRM" (fala de $\mathrm{P}_{3}$ no encontro coletivo de discussão), “ a pouca contrarreferência aos encaminhamentos na busca de diagnósticos clínicos" (diálogo com a professora após observação da $\mathrm{E}_{1}$ ), "a não compreensão da atividade" (fala de $\mathrm{P}_{2}$ no encontro coletivo de discussão), "as poucas condições de trabalho" (fala e $\mathrm{P}_{2}$ no encontro coletivo de discussão); esses aspectos, dentre outros, demonstraram que as docentes conseguem fazer seu trabalho por agirem cotidianamente de forma inventiva e criativa. Como afirma Mendes (2008), é em meio aos elementos prescritos, formais e informais, que eclodem concepções e práticas de gestão de pessoas e do trabalho a fim de balizar a organização do trabalho.

\section{Considerações finais}

Esta pesquisa apontou que as SRM presentes no município do Nordeste brasileiro pesquisado apresentam diversas variabilidades quanto à estrutura física e aos recursos pedagógicos. Nem todas as prescrições impostas pelo MEC em leis, portarias, notas técnicas e decretos, estão à risca sendo cumpridas, mostrando assim distanciamento entre o que é prescrito e o que é real, fato que não se deve estranhar segundo Dejours (2011b) e Molinier (2013). Para esses autores, sempre haverá essa lacuna nas organizações de trabalho, sendo impossível a elas alcançarem completamente as prescrições. Essa situação permitiu que as docentes se mobilizassem com sua inteligência astuciosa para dar conta das lacunas do trabalho. A mobilização subjetiva frente à defasagem encontrada permitiu o engendramento de adaptações, improvisações e transgressões à norma.
Essas variabilidades também foram encontradas quanto ao aspecto próprio da gestão do trabalho. Como as SRM pertencem a escolas diferentes e como lá fica apenas um professor por turno de funcionamento, foi bem indicativo que cada docente apresentou um modo de gestão diferenciado que a permitisse vivenciar a noção de pertencimento à instituição após demonstrar ações que se adequassem à dinâmica da escola que aloja a SRM. Assim, de modo muito particularizado, elas geram seu modus operandi a fim de que estar ativamente na escola, resistindo aos constrangimentos da organização de trabalho da qual faz parte, bem como propiciando sua formação identitária frente à tarefa. Fato visível quanto à estruturação dos cronogramas de atendimento e dos planos de AEE, bem como das estratégias de captação de recursos materiais e de autoafirmação frente ao coletivo.

É possível ainda afirmar que em meio a tantos constrangimentos da tarefa do AEE, as professoras das SRM da cidade pesquisada apresentam sofrimento ao desempenhar sua atividade, o que fez com que algumas delas solicitassem transferência das SRM. Contudo, o sofrimento da maior parte delas ainda é demonstrado de modo criativo, permitindo que a capacidade inventiva das docentes permaneça presente e personifique seus modos de resistência aos constrangimentos da tarefa do AEE. Contudo, como essas profissionais da educação têm adoecido, faz-se necessário que lhes sejam oportunizados espaços de discussão coletivos a fim de que saiam da invisibilidade e possam mostrar sua contribuição ao desenvolvimento do AEE no município. Espaços de discussões coletivas que permitam às docentes evidenciar o real do trabalho e suas mobilizações subjetivas. Esta recomendação pode ajudar as docentes na manutenção de sua saúde mental e na continuidade do desempenho do magistério em prol da inclusão. É imprescindível cuidar de quem cuida, incluir quem inclui.

\section{Referências}

American Psychiatric Association. (2014). Manual diagnóstico e estatístico de transtornos mentais. Artmed.

Antunes, R. (2018). O privilégio da servidão: o novo proletariado de serviços na era digital. Boitempo.

Clot, Y. (2010). Trabalho e poder de agir. Fabrefactum.

Dejours, C. (1992). A loucura do trabalho: estudo de psicopatologia do trabalho. Cortez.

Dejours, C., Abdoucheli, E., \& Jayet, C. (1994). Psicodinâmica do trabalho: contribuições da Escola Dejouriana à análise da relação prazer, sofrimento e trabalho. Atlas. 
Dejours, C. (2011a). Addendun: Da psicodinâmica à psicopatologia do trabalho. In S. Lancman \& L. Sznelwar (Orgs.), Christophe Dejours: Da psicodinâmica à psicopatologia do trabalho (pp. 57-123). Fiocruz.

Dejours, C. (2011b). Sofrimento e prazer no trabalho: a abordagem da psicopatologia do trabalho. In S. Lancman \& L. I. Sznelwar (Orgs.), Christophe Dejours: da psicopatologia à psicodinâmica do trabalho (pp. 167-183). Fiocruz.

Dejours, C. (2012a). Sexualidade e trabalho. Paralelo 15.

Dejours, C. (2012b). Trabalho vivo: trabalho e emancipação. Paralelo 15.

Fávero, E. A., Pantoja, L. M., \& Mantoan, M. T. (2007). Formação continuada a distância de professores para o Atendimento Educacional Especializado: aspectos legais e orientações pedagógicas. Seesp; Seed; MEC.

Gil, A. C. (2002). Como elaborar projetos de pesquisa. Atlas.

Giongo, C. R., Monteiro, J. K., \& Sobrosa, G. M. R. (2015). Psicodinâmica do Trabalho no Brasil: Revisão Sistemática da Literatura. Temas em Psicologia, 23(4), 803-814. http://pepsic.bvsalud.org/scielo. php?script=sci_arttext\&pid=S1413-389X2015000400002

Libâneo, J. C. (2001). Organização e Gestão da Escola: teoria e prática. Alternativa.

Lopes, E., \& Marquezine, M. C. (2012). Sala de Recursos no processo de inclusão do aluno com deficiência intelectual na percepção dos professores. Revista Brasileira de Educação Especial, 18(3), 487-506. https://doi.org/10.1590/ S1413-65382012000300009

Louzada, R. S. M. L., \& Oliveira, P. de T. R. de. (2013). Reflexões sobre a metodologia de pesquisa em Psicodinâmica do Trabalho. Revista do NUFEN, 5(1), 26-35.

Luckesi, C. C. (1994). Filosofia da Educação. Cortez.

Mendes, A. M. (Org.). (2008). Trabalho \& Saúde: O sujeito entre emancipação e servidão. Juruá.

Ministério da Educação. (2001). Diretrizes nacionais para a educação especial na educação básica. http://portal. mec.gov.br/cne/arquivos/pdf/CEB0201.pdf

Ministério da Educação. (2008). Política Nacional de Educação Especial na perspectiva da Educação Inclusiva. http://portal.mec.gov.br/arquivos/pdf/politicaeducespecial.pdf

Ministério da Educação. (2012). Documento orientador programa implantação de salas de recursos multifuncionais. http://portal.mec.gov.br/pnaes/194-secretarias-112877938/secad-educacao-continuada-223369541/ 17430-programa-implantacao-de-salas-de-recursos-multifuncionais-novo

Molinier, P. (2013). O trabalho e a psique: Uma introdução à psicodinâmica do trabalho. Paralelo 15.

Neves, M. Y. (1999). Trabalho Docente e Saúde Mental: A dor e a delícia de ser (tornar-se) professora [Tese de Doutorado, Universidade Federal do Rio de Janeiro].

Neves, M. Y., Seligmann-Silva, E., \& Athayde, M. (2004). Saúde mental e trabalho: um campo de estudo em construção. In A. Araújo, M. de F. Alberto, M. Y. Neves \& M. Athayde (Orgs.), Cenários do trabalho: subjetividade, movimento e enigma (pp. 18-49). DP\&A.

Nota Técnica n. 11, de 7 de maio de 2010. (2010). Orientações para a institucionalização na escola, da oferta do atendimento educacional especializado - AEE em salas de recursos multifuncionais. Ministério da Educação; Secretaria de Educação Especial. http://portal.mec.gov.br/index. php?option=com_docman\&view=download\&alias=17237-secadi-documento-subsidiario-2015\&Itemid=30192

Paisan, M. S., Mendes, E. G., \& Cia, F. (2017). Atendimento Educacional Especializado: aspectos da formação do professor. Cadernos de Pesquisa, 47(165), 964-981. https://doi.org/10.1590/198053144242

Resolução n. 4, de 2 de outubro de 2009. (2009). Institui Diretrizes Operacionais para o Atendimento Educacional Especializado na Educação Básica, modalidade Educação Especial. Ministério da Educação; Conselho Nacional de Educação. http://portal.mec.gov.br/dmdocuments/rceb004_09.pdf

Resolução n. 510, de 7 de abril de 2016. (2016). Determina diretrizes éticas específicas para as ciências humanas e sociais (CHS). Conselho Nacional de Saúde. http://conselho.saude.gov.br/resolucoes/2016/Reso510.pdf

Saviani, D. (2013). Histórias das ideias pedagógicas no Brasil. Autores Associados.

Sawaia, B. (2014). O sofrimento ético-político como uma categoria útil de análise da dialética exclusão/inclusão. In B. Sawaia (Org.), As artimanhas da exclusão: análise psicossocial e ética da desigualdade social (pp. 99-120). Vozes. 


\section{Séfora Lima de Figueiredo}

Mestre em Psicologia da Saúde pelo Programa de Pós-graduação em Psicologia da Saúde da Universidade Estadual da Paraíba (UEPB), Campina Grande- PB. Brasil.

E-mail: seforalf@gmail.com

(1) https://orcid.org/0000-0001-5360-8579

\section{Edil Ferreira da Silva}

Professor Doutor do Programa de Pós-graduação em Psicologia da Saúde e do Programa de Pós-graduação em Serviço Social da Universidade Estadual da Paraíba (UEPB), Campina Grande - PB. Brasil.

E-mail: edilsilva@uol.com.br

(1) https://orcid.org/0000-0002-0919-5743

Endereço para envio de correspondência:

Av. Sapé, 434, Edifício Brisa do Mar, apto. 502, Bairro Manaíra. CEP: 58038-380. João Pessoa - PB. Brasil,

Recebido 20/10/2019

Aceito 15/01/2021

Received 10/20/2019

Approved 01/15/2021

Recibido 20/10/2019

Aceptado 15/01/2021

Como citar: Figueiredo, S. L. de, \& Silva, E. F. da. (2022). Desafios do fazer docente nas salas de recursos multifuncionais (SRM). Psicologia: Ciência e Profissão, 42, 1-14. https://doi.org/10.1590/1982-3703003230191

How to cite: Figueiredo, S. L. de, \& Silva, E. F. da. (2022). Challenges of teaching in multifunctional resource rooms (SRMs). Psicologia: Ciência e Profissão, 42, 1-14. https://doi.org/10.1590/1982-3703003230191

Cómo citar: Figueiredo, S. L. de, \& Silva, E. F. da. (2022). Desafíos del Hacer Docente en las Salas de Recursos Multifuncionales (SRM). Psicologia: Ciência e Profissão, 42, 1-14. https://doi.org/10.1590/1982-3703003230191 